Running Head: TRANSCENDENCE IN MEDIA

Exploring the Spirit in U.S. Audiences: The Role of the Virtue of Transcendence in Inspiring

Media Consumption

by

Sophie H. Janicke-Bowles, Arthur A. Raney, Mary Beth Oliver, Katherine R. Dale, Robert P

Jones, and Daniel Cox

Sophie H. Janicke-Bowles (Ph.D., Florida State University, 2013) is an assistant professor in the School of Communication at Chapman University. Her research interests include the role that new and traditional media play in promoting and affecting character development, selftranscendent emotions, prosocial behavior, and well-being. bowles@chapman.edu; https://orcid.org/0000-0003-4162-3717

Arthur A. Raney (Ph.D., University of Alabama, 1998) is the James E. Kirk Professor of Communication in the College of Communication \& Information at Florida State University. His research interests include how and why we enjoy media entertainment, with specific attention to the role of morality and moral emotions in those processes.

araney@fsu.edu

Mary Beth Oliver (Ph.D., University of Wisconsin, Madison, 1991) is the Donald P. Bellisario Professor of Media Studies in the Department of Film/Video \& Media Studies at Pennsylvania State University. Her research interests include the psychological and social effects of media, with an emphasis on media and emotion, media and social cognition, and entertainment. mbo1@psu.edu

Katherine R. Dale (Ph.D., The Ohio State University, 2015) is an assistant professor in the College of Communication \& Information at Florida State University. Her research interests include positive media psychology, media effects, and intergroup interaction. krdale@fsu.edu 
Robert P. Jones (Ph.D., Emory University, 2002) is the CEO at the Public Religion Research Institute. His research interests include public opinion research, the impact of demographic changes on religious affiliation and behavior, and the interactions between race, politics, and religion rjones@prri.org

Daniel Cox (Ph.D., Georgetown University, 2015) is the Research Director at the Public Religion Research Institute. His research interests include survey research, youth politics, and religion.dcox@prri.org

Correspondence should be addressed to Sophie H. Janicke-Bowles, School of Communication, Chapman University, 1 University drive, Orange, CA 92866. E-mail: bowles@chapman.edu

Abstract

Little is yet known about audiences who routinely seek out media content that is inspirational in nature (Oliver et al., 2018). The current study expands the research on inspirational media by utilizing a nationally representative sample of U.S. audiences $(n=2,016)$ to explore relationships between inspiring media exposure, trait transcendence, and self-transcendent emotions. Results show that media content is a reliable source for everyday self-transcendent emotional experiences in U.S. audiences. These experiences are most frequently encountered by persons with high levels of trait spirituality and gratitude. The profile of U.S. audiences that seek out inspiring media is discussed.

Keywords: Inspiring Media, Spirituality, Gratitude, Self-transcendent emotions, U.S. Audience

This project was made possible through the support of a grant from the John Templeton Foundation. The opinions expressed in this publication are those of the authors and do not necessarily reflect the views of the John Templeton Foundation. 


\section{Exploring the Spirit in U.S. Audiences: The Role of the Virtue of Transcendence in Inspiring Media Consumption}

Recently, mass communication researchers have begun to explore media content that is inspirational in nature, content that is often described as touching, moving, thought-provoking, eliciting goose bumps, and leaving audiences with a lump in their throat (Oliver et al., 2018). Generally, inspirational media content portrays humanity’s better nature: altruism, kindness, compassion, perseverance, and love. Such content can be found across many platforms and formats, including music, TV shows, films, radio, news, and social media. Initial research suggests that some people are more likely to seek out inspiring content or to feel more inspiration upon exposure than others. In the most extensive audience study to date, Raney, Janicke, Oliver, Dale, Jones, and Cox (2018) found that females, younger audiences, minorities, and those with more education were generally more likely to report having felt inspired by a variety of different media sources, as were those with higher levels of trait empathy and need for affect.

Understanding inspirational media is important for communication scholars because of the potential positive effects associated with consumption. Inspiring content can elicit selftranscendent emotions (e.g., awe, gratitude, elevation), which have been found to benefit different aspects of well-being, including prosociality (Schnall, Roper \& Fessler, 2010; Stellar et al., 2017), connectedness (Janicke \& Oliver, 2017), spirituality (Saroglou, Buxant, \& Tilquin, 2008), and life satisfaction (Diessner, Solom, Frost, Parson, \& Davidson, 2008). The resulting self-transcendent media experiences ultimately draw us out of our self-focused consciousness to open ourselves to others (Oliver et al., 2018; Stellar et al., 2017). A greater understanding of those experiences can better equip educators, industry leaders, content creators, healthcare 
providers, counselors, and other concerned individuals to promote and increase inspirational media consumption. As such, the study holds promise to better illuminate the potential for media to create positive individual and social change.

In pursuit of this understanding and building on past research, the current study explored the role of inspiring media within the lives of the American public. The project was guided by three primary goals. First, Raney and colleagues (2018) reported that most Americans have been inspired by media at some point in their lives, but it is yet unknown how frequently they seek it out. Thus, our first research goal was to explore the frequency of inspiring media exposure and possible changes in that frequency over time. As a part of this, we also wanted to explore how audiences were encountering and possibly sharing inspiring media. Second, Raney et al. (2018) provided an initial exploration of personality traits that might explain inspiring media exposure, based on those shown to be related to eudaimonic media in general (see Oliver \& Raney, 2011). However, a systematic analysis of personality factors and their theoretical contribution to selftranscendent media experiences is still missing. Consequently, our second research goal focused on exploring transcendent traits—namely, spirituality and gratitude-as specific predictors of inspiring media experiences. Lastly, self-transcendent emotions can be elicited by both mediated and non-mediated activities (e.g., connecting with close friends or family, being in nature), but it is unclear which better predicts day-to-day self-transcendent experiences. Therefore, our third research goal explored the role that inspiring media (vs. non-mediated) experiences play in the everyday elicitation of self-transcendent emotions among a representative U.S. sample.

To reach these goals, two waves of panel data from a representative sample of the U.S. population were analyzed. Wave $1(n=3,006)$ was the basis for Raney et al. (2018); in Wave 2, $67.1 \%(n=2,016)$ of those individuals were surveyed again to investigate new relationships 
between variables and to measure change across time in others. The survey design, analysis, and interpretation were guided by theories and concepts from media and positive psychology; we review those now.

\section{Prevalence of Inspiring Media Consumption}

Most individuals report having had emotional reactions that they associate with inspiration when consuming media (Raney et al., 2018), but what is not clear is how often they have such experiences. Such information is crucial given the potential benefits of those experiences to psychological well-being (e.g. Diessner et al., 2008; Janicke \& Oliver, 2017; Saroglou et al., 2008). Thus, to begin, we explored:

RQ1: How often does the current U.S. audience feel inspired by media content?

With video-on-demand and streaming service, online news, and social media, consumers have the opportunity to consume more content than ever before. With the sheer increase of information available, inspirational content has also become more common and readily available. Numerous news services have started to provide positive and inspiring stories for their consumers. For example, in July 2015, USA Today introduced a new section that invites consumers to submit "stories of real people performing positive acts," which are also published on Facebook (USA Today Humankind, 2015, para. 1). In June 2018, Huffington Post introduced a new series that focuses on “elevating stories about kindness” (Huffpost PR team, 2018). Inspirational content is among the highest performing Facebook posts in terms of user engagement (Peters, 2019). Moreover, online users are more likely to share positive content with others in several ways (e.g., Berger \& Milkman, 2012; Raney et al., 2018; Ji et al., 2019); recent experimental research provided more evidence of this fact with inspiring (vs humorous) videos (Clayton et al., in press). Thus, audiences today may be likely to encounter inspiring media, 
engage with it in some way, and to pass it along to others. Evidence of such a trend would lend further support to the broaden-and-build theory (Fredrickson, 2001), which contends that positive emotional experiences broaden our perspectives and build our personal resources, leading to an upward spiral of human flourishing. To explore the extent to which inspiring media might be contributing to this spiral and in light of the apparent increase in content availability, we compared Wave 1 and Wave 2 responses with the expectation that:

H1a: U.S. audiences will actively seek inspiring media more over time; and,

H1b: U.S. audiences will be increasingly more likely to share inspiring media content with others over time.

\section{Transcendence and Inspiring Media Consumption}

Perhaps it goes without stating, but inspiring media leads to inspiration among audience members. According to Thrash and Elliot (2003), inspiration (1) is evoked, rather than initiated intentionally [in the current case, evoked by media content], (2) is transcendent in that it is elicited by or includes the experiences of something larger then oneself [more on this below], and (3) implies motivation and, thus, energizes behavior [e.g., sharing the content with others]. Thus, a key component and defining characteristic of (mediated) inspiration is transcendence.

According to the virtues in action (VIA) framework, transcendence is one of six universally observed human virtues that can impact well-being (Peterson \& Seligman, 2004). Transcendence is the virtue to strive for purpose and meaning greater than oneself and to connect with humanity’s higher nature. The VIA framework further states that each virtue is manifest through various “character strengths,” or traits that govern a person’s thoughts, actions, and emotions (Park, Peterson, \& Seligman, 2004). Transcendence is thought to be manifest through five-character strengths: gratitude, spirituality, hope, an appreciation for beauty, and humor 
(Peterson \& Seligman, 2004). For example, a person in awe of the beauty of nature or encouraging a friend to persevere through hard times is manifesting the traits of appreciation and hope, respectively. As a result, s/he is enacting, expressing, and further developing the virtue of transcendence. The emotions and motivation evoked when consuming inspiring media can also then promote the virtue of transcendence and its associated traits.

But we know that traits also matter in the selection of media, both on a conscious and unconscious level (selective exposure; e.g., Bryant \& Davies, 2006; see also Bartsch \& Viehoff, 2010). Given the nature of inspiration, it stands to reason that audience members with stronger tendencies toward transcendence-related traits might seek out such experiences more often and be more motivated to share them with others. Therefore, we hypothesized:

H2: U.S. audience members reporting higher levels of transcendence-related traits will (a) come across inspiring media more often and (b) share it with others more often.

The cost constraints of the current panel design, unfortunately, did not permit an in-depth examination of all five transcendence-related traits in the current study. Two of the five were examined: gratitude and spirituality. Gratitude was selected because it has been found to be one of the most often occurring portrayals within inspiring media (e.g., Dale et al., 2017a; Dale et al., 2017b). Spirituality was chosen because it is the variable (arguably) most strongly related to selftranscendent experiences in the existing literature (e.g., Saroglou et al., 2008; Van Cappellen et al., 2013).

Gratitude. Gratitude is an emotional state of thankfulness toward a personal benefactor or an appreciation for the positive things in life in general (e.g., Wood, Froh, \& Geraghty, 2010). According to the VIA framework, gratitude has been defined as the tendency to generally be aware of the good things that happen in life, to not take those things for granted, and to express 
thanks often (Park et al., 2004). Research in the field of positive psychology has shown that state gratitude is one of the strongest predictors of many well-being variables, including life satisfaction (Emmons \& McCullough, 2003; Lyubomirsky, Dickerhoof, Boehm, \& Sheldon, 2011), strengthening and building of social bonds (McCullough, Kilpatrick, Emmons, \& Larson, 2001; McCullough \& Tsang, 2004), and prosocial behavior (Bartlett \& DeSteno, 2006; Ma, Tunney, \& Ferguson, 2017; McCullough et al., 2001).

The investigation of gratitude in the context of media is relatively new. One group of scholars recently analyzed the presence of 20 transcendent-related depictions in inspiring content across a multitude of media platforms including YouTube videos (Dale, et al., 2017b) and movies and TV shows (Dale et al., 2017a). One consistent finding across these platforms was that emotional elicitors and character portrayals of gratitude were exceedingly common. Selective exposure theory argues that media users come to learn-via classical conditioning, excitation transfer, mere exposure, and implicit memory (see Bryant \& Davies, 2006)— associations between particular content and outcomes. As a result, we expected that audiences with a strong disposition toward gratitude may be more likely to experiences inspiration from media:

H3: Trait gratitude will predict inspiring media experiences.

Spirituality. Spirituality is a multidimensional concept involving the experience of and encounters with transcendence, the sacred, connectedness, and meaning or ultimate truth (e.g., Elkins, Hedstrom, Hughes, Leaf, \& Saunders, 1988; Emmons, 2006). For some, spirituality necessarily involves the divine; for others, it does not. It has been described as a way of being, a way of experiencing and understanding life, a quality, a trait, a sense, and an activity, among many others (see Janicke \& Raney, 2016). As a result, the operationalization and measurement 
of spirituality on surveys has been quite varied.

According to Emmons (2006), the scientific study of spirituality developed along "three levels of analysis: spirituality as general trait, spirituality as reflected in personal goals and intentions, and spirituality as reflected in specific emotions and emotional processes” (p. 63). Janicke and Raney (2016) argued that operationalizing spirituality as a trait lends itself well to media studies, especially those concerned with selective exposure processes. We took the same perspective in this project. Two specific aspects of trait spirituality were examined: universality (i.e., belief in the unity and purpose of life; Piedmont, 1999) and search for meaning in life (Park et al., 2004; Steger, Frazier, Oishi, \& Kaler, 2006). These two aspects of trait spirituality were selected because they directly reflect the VIA framework, in which spirituality is defined as a belief system involving a higher purpose and meaning in life that shapes the conduct of life (Park et al., 2004). Admittedly, measuring additional aspects of trait spirituality would have been ideal. Nevertheless, we hypothesized:

H4: Spirituality—operationalized as a trait involving (a) the search for meaning in life and (b) universality—will predict inspiring media experiences.

As noted above, spirituality can also be characterized as an activity, often associated with the pursuit of spirituality as a personal goal. Such activities can involve rites and rituals associated with a particular religious faith, or not. Regardless, they are a part of the "conduct of [one’s spiritual] life,” as noted by Park and colleagues (2004). Therefore, we measured both, forecasting that:

H5: Attendance at (a) spiritual (but not religious) and (b) religious gatherings will predict inspiring media experiences.

\section{Self-Transcendent Experiences and Inspiring Media Consumption}


As noted above, inspiring media can elicit self-transcendent emotions (Oliver, et al., 2018). Self-transcendent emotions are a particular set of positive emotions including awe, gratitude, elevation, hope, and admiration (e.g., Algoe \& Haidt, 2009; Haidt \& Morris, 2009). They are generally elicited by (moral) virtue, goodness, or beauty as portrayed by other people and their actions, or nonhuman agents such as nature or art. Each self-transcendent emotion has its own specific set of elicitors, but together these emotions share an outward orientation, increased approach behavior, and potential for building social resources (Stellar et al., 2017). These emotional experiences subsequently increase the likelihood that one may experience further instances of self-transcendence in the future (per the broaden-and-build theory; Fredrickson, 2001).

Because research has demonstrated a relationship between inspiring media use and the experience of self-transcendence (Dale et al., 2017b; Thrash, Elliot, Maruskin, \& Cassidy, 2010), spirituality (Raney et al., 2018; Van Cappellen et al., 2013), and gratitude (Stellar et al., 2017), it seems reasonable to assume that persons high in transcendence-related traits—such as spirituality and gratitude_-may be more likely to seek out inspiring media and feel inspired by it (hence, H3 and H4). Past research has found that other personality variables—specifically, need for affect and empathy_-are important to explain exposure to more broadly defined eudaimonic content (see Oliver \& Raney, 2011), and Raney et al. (2018) found that these variables also explain exposure to inspiring content. However, given the centrality of transcendence in inspiration (Thrash \& Elliot, 2003), we contend that transcendence-related traits may be better explanatory variables of experiencing inspiration from media than the more general ones. This prediction is in line with theoretical reasoning that differentiates other-focused, self-transcendent 
media experiences from self-focused-but-nevertheless-meaningful, eudaimonic ones (Oliver et al., 2018). Consequently, we expected:

H6: Traits related to the virtue of transcendence-gratitude and spirituality (measured as universality and search for meaning)—will explain more variance in inspiring media experiences than traits associated with more general eudaimonic media exposure (need for affect, empathic concern, perspective taking).

Furthermore, as noted, several experimental studies have demonstrated that inspiring media can elicit self-transcendent experiences (e.g., Dale et al., 2017b; Van Cappellen et al., 2013). However, many non-mediated stimuli can also elicit self-transcendent experiences, including being with friends, being in nature, praying, engaging in religious activities, meditating, or doing yoga (Haidt, 2003; Haidt \& Keltner, 2004; Vago \& Silbersweig, 2012; Yaden, Haidt, Hood, Vago, \& Newberg, 2017). Thus, the benefitting influence of these emotional experiences may be triggered by a variety of sources in one's daily life. We were curious about the extent to which such experiences were due to inspiring media. Thus, we asked:

RQ2: What role do recent inspiring media experiences play in the routine experience of self-transcendence?

\section{Method}

\section{Sample}

Data were collected in two waves; the two surveys contained unique and repeated questions. Surveys were completed by participants of AmeriSpeak, a probability-based panel designed to be representative of the national U.S. adult population, run by NORC at the University of Chicago. ${ }^{1}$ Wave 1 data $(n=3,006)$ were collected in January and February 2016;

\footnotetext{
${ }^{1}$ A technical overview of the AmeriSpeak panel can be found at https://amerispeak.norc.org/aboutamerispeak/Pages/Panel-Design.aspx
} 
they served as the basis for the analysis previously reported by Raney and colleagues (2018).

Wave 2 data were collected in February and March 2017, with 67.1\% $(n=2,016)$ of the original sample completing the second survey. Wave 1 data from all 2,016 Wave 2 participants were matched by case ID and merged into a combined data set for the analyses.

Responses in both waves were weighted to represent the current U.S. population. First, panel base weights were calculated for every household based on the probability of selection from the NORC National Frame. Household-level weights were then assigned to each eligible adult in every recruited household. Next, the sample demographics were balanced to match the U.S. population parameters for gender, age, education, race, ethnicity, housing type, and telephone usage. The telephone-usage parameter was derived from an analysis of the National Health Interview Survey. All other weighting parameters were derived from the U.S. Census Bureau’s Current Population Survey. The sample weighting was accomplished using an iterative proportional fitting process that simultaneously balanced the distributions of all variables. Weights were trimmed to prevent individual interviews from having too much influence on the final results. All analyses were calculated with the weights applied to the dataset. The margin of error for the surveys was $+/-2.5 \%$ in Wave 1 and $+/-3.1 \%$ in Wave 2, at the $95 \%$ level of confidence. The surveys were reviewed and approved by the Institutional Review Boards at (MASKED FOR REVIEW) and NORC/University of Chicago.

\section{Measures}

The survey instrument was collaboratively designed by researchers from three universities and researchers from the Public Religion Research Institute (PRRI); the project was funded by the John Templeton Foundation. ${ }^{2}$

\footnotetext{
2 The John Templeton Foundation requests that all awardees include this statement in manuscripts related to their sponsored research: "This project was made possible through the support of a grant from the John Templeton
} 
Overall media exposure (Wave 1 only). Participants indicated on a scale $(1=$ never, $8=$ several times a day) how often they spend time with eight media forms: watching TV $(M=6.80$, $S D=1.67)$, watching movies $(M=5.18, S D=1.65)$, reading the news $(M=5.84, S D=2.16)$, watching online videos $(M=4.88, S D=2.38)$, using social media $(M=5.60, S D=2.82)$, listening to radio programs or podcasts $(M=5.14, S D=2.52)$, listening to music $(M=6.82, S D$ $=1.60)$, and reading fiction or non-fiction books $(M=4.03, S D=2.26)$.

Inspiring media experiences (Wave 2 only). Inspiring media experiences were assessed in two ways. First, participants indicated how often in the past month they had "felt moved, touched, or inspired while watching or listening to something in the media or on the internet.” This general assessment was reported on a Likert-type scale, ranging from 1 (never) to 6 (at least once a day). Second, participants indicated how recently they had felt moved, touched or inspired ( 1 = never been inspired, 5 = inspired in the last week) by each of eight media forms: watching a TV show $(M=3.89, S D=1.18)$, watching a movie $(M=3.70, S D=1.15)$, listening to a radio program or podcast $(M=3.27, S D=1.38)$, reading a book $(M=3.14, S D=1.30)$, reading a news story $(M=3.61, S D=1.30)$, listening to a song or piece of music $(M=4.19, S D$ $=1.10)$, watching an online video $(M=3.43, S D=1.40)$, and using social media, like Facebook $(M=3.29, S D=1.59)$. An overall recency of inspiring media experience score was calculated for each participant by averaging responses to each of the eight medium-specific recency items $(\alpha=.801, M=3.57, S D=.848)$

Inspiring Media Exposure (Waves 1 and 2). Independent of media type, participants were asked how they came across the most recent inspiring content: specifically searching for it, recommended by a friend or family member, as an advertisement, or just by chance. Participants 
could indicate which of those answers were true for them. Each answer was then recorded into a dummy variable expressing their indication for it (1) or not (0). They were also asked whether they shared the inspiring content with a friend or family member in any way (yes/no).

Comparisons between the two waves are analyzed in H1.

Inspiring non-mediated activities (Wave 1 only). As noted above, many non-mediated stimuli are associated with the experience of inspiration and self-transcendent emotions. Participants indicated how often they participate in several such activities ${ }^{3}$ : spending time with friends $(M=5.14, S D=1.63)$, meditating $(M=3.17, S D=2.48)$, gardening, hiking, or enjoying the outdoors $(M=4.63, S D=1.93)$, doing yoga $(M=1.75, S D=1.48)$, or praying outside of religious services $(M=4.82, S D=2.74)$.

Self-transcendent experiences (Waves 1 and 2). Self-transcendent experiences were assessed with seven items that tapped into the appraisals of various self-transcendent emotionsincluding elevation, compassion, awe, meaning, and gratitude-as previously assessed (Oliver et al., 2012). Respondents in both waves reported how often they experienced each selftranscendent emotion in the last month, using a Likert-type scale, ranging from 1 (never) to 6 (at least once a day). Sample items include "How often in the last month did you feel particularly connected to the world around you? ... felt like you were part of something much larger than yourself? ... felt a sense of compassion for people you don’t even know.” The reported frequency of self-transcendent emotional experiences did not differ between the two waves: $t(2006)=1.18, p=.236$; Wave $1: \alpha=.822, M=3.95, S D=1.11$; Wave $2: \alpha=.856, M=3.98$, $S D=1.01$

\footnotetext{
${ }^{3} 1=$ Never, 2 = Seldom; $3=$ Few times a year; $4=$ Once or twice a month; $5=$ Once a week; $6=$ More than once a week, 7 = Once a day, 8 = Several times a day
} 
Personality traits. To expand our understanding of self-transcendent media experiences, we explored personality variables related to gratitude and spirituality. Short-forms scales were used because of time and cost constraints of the panel design. Item selection for the short-form scales was based on the performance of individual items as reported in past research, as well as conceptual fit between an item and the purposes of the current study. Each item used a Likerttype scale measuring how well the item describes the participants; the scale ranged from 1 (not at all well) to 5 (exactly).

Gratitude (Wave 2 only) was measured with two items from the trait gratitude questionnaire by McCullough et al. (2002). Higher values indicated stronger trait gratitude $(r=$ $.634, p<.001, M=3.97, S D=.882)$.

Spirituality was operationalized with four measures: two in line with "spirituality as trait”; two in line with "spirituality as personal goal” (Emmons, 2006). Search for meaning in life (Wave 2 only) was assessed as a trait with two items from the search for meaning in life questionnaire by Steger et al. (2006). The higher the value, the stronger the tendency to search for meaning in life $(r=.592, p<.001, M=3.19, S D=1.03)$. Universality (Wave 1 only) was measured as a trait with two items from previous research (Piedmont, 1999), with higher values indicating a greater belief in the unity of life $(r=.561, p<.001, M=3.45$, $S D=.974)$. The two personal goal-oriented items were attendance at spiritual (not religious) gatherings $(M=2.62, S D$ = 1.54; Wave 1 only) and attendance at religious gatherings (excluding weddings and funerals) $(M=3.16, S D=1.67 ;$ Wave 1 only). Both items were assessed on a Likert-type scale ranging from 1 (never attending) to 6 (attending more than once a week). Attendance at spiritual (not religious) and religious gatherings correlated significantly with each other $(r=.679, p<.001)$. 
In addition, several traits (all Wave 1 only) previously associated with eudaimonic media (Oliver \& Raney, 2011) were analyzed, including 2-item short-form versions of need for affect (Appel, Gnambs, \& Maio, 2012; $r=.468, p<.001, M=3.57, S D=.879$ ), empathic concern (Davis, 1980; $r=.258, p<.001, M=3.11, S D=.629$ ), and perspective taking (Davis, 1980; $r$ $=.561, p<.001, M=3.96, S D=.804)$, with higher scores indicating a greater expression of each trait.

Demographics (Wave 1 only). A range of demographics were assessed including gender, age, ethnicity, educational attainment, marital status, and political affiliation. Tables 1 and 2 summarize the demographics per recency of inspiration felt from different media platforms. We offer these as a portrait of the current U.S. audience for inspiring media, similar to Raney et al. (2018).

Table 1 and 2 here--

\section{Results}

\section{Inspiring Media Exposure}

Participants reported having felt inspired by something in the media or on the internet almost weekly $(M=3.89, S D=1.32)(\mathrm{RQ} 1)$. A plurality of respondents indicated having felt inspired a few times a week (31.1\%), followed by almost every day (19.8\%), and once or twice a month (19.5\%). More than one in eight (12.6\%) said they felt moved, touched, or inspired by media on a daily basis.

Additionally, we compared the ways people came across inspiring media across the two years (H1a), using McNamar statistics for dependent data. A marginally significant difference was observed between Waves 1 and 2 in terms of people indicating that they specifically searched for inspiring content (Wave 1: 5.2\%, Wave 2: 6.6\% $p=.06$ ), with the trend leaning 
toward more people actively searching for inspiring content in the most recent data-collection cycle, lending marginal support to H1a. Chance encounters with inspiring media were less common in Wave 2, with $67.7 \%$ indicating that they came across inspiring media randomly, as compared to $70.8 \%$ in Wave $1(p=.023)$. No differences were observed between the waves in terms of encountering inspiring content because of recommendation from friends or family members (Wave 1: 14.7\%, Wave 2: 15.2\%, $p=.695$ ) or because of an advertisement (Wave 1: 6.1\%, Wave 2: $6.6 \%, p=.540)$.

With regard to sharing behaviors (H1b), respondents reported less sharing behavior in Wave 2 (58.6\% shared) compared to Wave 1 (62.2\% shared, $p=.006)$, meaning H1b was unsupported.

To investigate H2, three logistic regression analyses were conducted with gratitude and spirituality (search for meaning in life and universality) expected to impact (1) search for inspirational media content, (2) randomly coming across inspirational media content, and (3) sharing behavior (all measured at Wave 2) as a binary outcome variable. Neither gratitude nor spirituality predicted searching for content $\left(\chi^{2}(3)=6.645, p=.084\right)$ or randomly coming across content $\left(\chi^{2}(3)=5.377, p=.146\right)$, leaving H2a unsupported. However, increased sharing behavior was explained by trait gratitude $\left(\chi^{2}(2)=56.44, p<.001\right.$, Nagelkerke $R^{2}=.071$; $\mathrm{B}=.411, p<$ $.001, \operatorname{Exp}(B)=1.508)$ and universality $(B=.245, p<.001, \operatorname{Exp}(B)=1.27)$; however, search for meaning in life did not predict sharing. Thus, H2b was partially supported.

\section{Virtue of Transcendence and Inspiring Media Experiences}

To investigate H3-6, a hierarchical regression procedure was conducted with the overall recency of inspiring media experience score regressed on the demographic variables, attendance at religious and spiritual gatherings, and the various personality traits. The results indicated that 
females and people with higher education were particularly prone to feel inspired by media (replicating Raney et al., 2018). For the personality variables of interest, as expected, gratitude (H3) and spirituality (search for meaning in life [H4a] and universality [H4b]) were significant predictors of inspiring media experiences. In contrast, neither attendance at spiritual (H5a) nor religious (H5b) gatherings were significantly contributing to inspiring media use. Finally, as expected (H6), traits related to the virtue of transcendence (descriptively) explained more variance than the other eudaimonically oriented traits (see Table 3). Combined, all personality variables explained $10.2 \%$ of the variance of inspiring media experiences, with the transcendence-related predictors alone contributing 7.1\%. -Insert Table 3 here

\section{Self-Transcendent Emotional Experiences and Inspiring Media Experiences}

Finally, we were interested in the role inspiring media experiences play in day-to-day self-transcendent emotional experiences, as compared to non-media elicitors of those emotions (RQ2). To explore these relationships, a hierarchical regression analysis was conducted with demographic variables, overall non-media inspiring activities, overall media exposure, attendance at religious and spiritual gatherings, self-transcendent emotional experiences (from Wave 1), and overall inspiring media experiences as predictors of the frequency of selftranscendent emotional experiences in Wave 2 (see Table 4). As to be expected, selftranscendent experiences at Wave 1 explained a sizeable amount of the variance in selftranscendent experiences in Wave 2 (18.7\%). Beyond that, non-media inspiring activities (10.2\%) and overall inspiring media experiences (10\%) explained nearly equal amounts of variance for self-transcendent emotional experiences. Demographics, general media exposure 
and attendance at religious or spiritual gatherings explained negligible proportions of variance in self-transcendent emotional experiences (in Wave 2).

- Insert Table 4 here-_

\section{Discussion}

The goals of this study were three-fold: (1) to investigate the prevalence of and potential changes in how Americans come across and share inspiring media, (2) to expand our knowledge of the role of trait transcendence-particularly, the aspects related to gratitude and spiritualityin inspiring media consumption, and (3) to better understand the role of inspiring media experiences (compared to non-mediated ones) in the routine elicitation of self-transcendent emotions.

With regard to the first goal, it is increasingly clear that inspiring content plays a significant role in the routine media diets of many Americans. Nearly two-thirds (63.5\%) of the respondents reported being inspired by media at least a few times a week, with $12.6 \%$ reporting being inspired by media at least once per day. Clearly this is a phenomenon deserving of more scholarly (and industry) attention. To that end, our hope is that the extensive demographic profile of the American inspirational media audience provided in Tables 1 and 2 can serve as the basis for new research ideas.

Further, the data reveal quite a bit about how inspiring media is encountered by audiences. As outlined by selective exposure and related media-use approaches (Bryant \& Davies, 2006; Bartsch \& Viehoff, 2010), media content is sought after based on various emotional, functional, conscious, and unconscious motivations. However, the vast majority of people in our sample came across inspiring media by chance (67.7\%). One interpretation of this finding is that it underscores the longstanding critique of the uses-and-gratifications approach 
that media choices are not always conscious (e.g., Vorderer, 1992). In fact, only 6.6\% of the current sample searched for inspiring content purposefully. Moreover, people high in transcendent virtue—-measured as trait gratitude and spirituality—did not search for inspirational media more nor did they come across it any more than people at lower levels of transcendence. Thus, quite often inspiring media may be not consumed as a conscious, need-satisfaction tool, even for those persons higher in transcendent-related traits. Rather, the data suggest that those higher in transcendent-related traits may be more likely to feel—or they may be more sensitive to feeling-inspired by different types of media more frequently (H3 and H4), independent of how they come across it. This makes the personality traits related to transcendence unique to the experience of inspiration, supporting Thrash and Elliot's (2003) conceptualization of transcendence as an integral part of inspiration. Also, caution is strongly encouraged in interpreting these findings as suggesting that people do not or rarely seek out inspiring media. The item used asked only about the most recent inspiring media experience. Given the prevalence of inspiring media use reported, we think that these findings suggest that in addition to seeking out inspiring media, individuals are also routinely "surprised” by inspiration, via inspirational advertisements or news stories, for example. Future research should explore the possibility in greater detail.

Additionally, people higher in transcendent traits were quite likely to share the inspirational content they experienced with friends or family members (H2b). Once more, fitting with the theory of inspiration (Thrash \& Elliot, 2003), people higher in transcendence-related traits not only find more media inspiring (H6), but once they feel inspired, they also have a greater tendency to share those experience with others. This echoes the motivational component of inspiration discussed by Trash and Elliot (2003). One conclusion to draw is that people with 
strong transcendent character traits may be more likely to be consumers who propel and spread inspiring media to others. They might be the "influencers" who could have real impact in making inspiring messages go viral, indicating to media gatekeepers (e.g., film studios, advertisers) the forms of inspiring media that audiences prefer to consume. Specifically, within the social media landscape, the consumers of content have also become the producers (or, at a minimum, the retransmitters) of content. For media researchers, it may not be sufficient anymore to only consider how people come across certain types of media, since that assumes a reception model in which the consumer is dependent on gatekeepers' distribution of content. It is now pertinent to also consider what consumers do with the content they consume, as well as the effects of creating original content on their own. Knowing who the audiences are that consume inspiring content and what they do with it (e.g., share, recreate, comment, review) are important factors to better understand the dynamics of such reception trends across the media landscape.

With regard to goal 2, the findings indicate that transcendent character traits are of great importance to the experience of emotional gratifications with inspiring media. Two specific character strengths (based on the VIA framework) associated with the virtue of transcendencegratitude and spirituality — were the strongest predictors of inspiring media exposure, more so than numerous demographic variables, attendance at religious or spiritual gatherings, and other traits previously associated with eudaimonic media selection (Oliver \& Raney, 2011). These results offer some of the first empirical support for the proposal that eudaimonic media should be conceptualized along a continuum from self-oriented “meaningful content” on one end to othersoriented “self-transcendent content” (see Oliver et al., 2018). The current study suggests that U.S. audience members higher in transcendence (at least as manifest in spirituality and gratitude) are more likely to feel inspired via media than people lower in the trait. On the other hand, the 
eudaimonic traits (need for affect, perspective taking, empathic concern) were weaker explanatory variables of inspiring media experiences, indicating a potentially useful expansion of eudaimonic media motivations as previously established by Oliver and Raney (2011). Better understanding who the audiences are that seek out media that elicits self-transcendent emotions_-as compared to media that is contemplation-evoking, poignant, and moving (Bartsch, Kalch \& Oliver, 2014)—could be important for researchers designing experimental studies of inspiring (or eudaimonic) media effects and content creators who aim to better understand their target audience. Future research is needed to explore this proposition in more detail. Moreover, given the current findings, future research could expand to additional transcendent character traits as explanatory variables of inspirational media use, perhaps exploring the other dimensions of transcendence (i.e., hope, appreciation of beauty, humor; Park et al., 2004) for a comprehensive model to explain inspiring media selection and consumption.

Curiously, attendance at spiritual and at religious gatherings as markers of spirituality were unrelated to inspiring media experiences, when controlling for demographic variables (H5). It is possible that some people choose to seek and find inspiration with like-minded individuals in group settings, while others prefer to encounter inspiration via media. Thus, attendance at spiritual and religious events may be an outcome, rather than a predictor, of inspiring media exposure. More research is needed to disentangle the complexity of spirituality and its relationship to inspiring media exposure.

In reference to goal 3, to our knowledge, this is the first study to compare the "power" of inspiring media to elicit self-transcendent emotions with other sources, with promising news for the former. With no doubt, non-media activities related to transcendence-particularly prayer and meditation-remain extremely important in the lives of audiences, leading them to feel 
connected to those around them, to experience feelings of gratitude, and to forge a stronger connection with nature and earth. However, the survey results provide strong evidence that inspiring media consumption is also an important factor in the elicitation of self-transcendent experiences. That is, consuming inspiring media seems to be an excellent option for people to get their daily dose of self-transcendence in life, which we know has various beneficial well-being effects (i.e., Diessner et al., 2008; Stellar et al., 2017). Moreover, the earlier evidence suggests that the experience of self-transcendence specifically via media may increase the tendency for people to share and seek out similar content in the future, leading to an upward spiral of selftranscendence as argued by the broaden-and build theory (Fredrickson, 2001). Future research should more directly test the role of inspiring media in the upward spiral of human flourishing, perhaps through a longitudinal study of inspiring media consumption.

Despite the generalizable knowledge gained through the representativeness of our sample, the nature of the study has some limitations. First, the data are correlational. Thus, we cannot make causal arguments for the relationship between transcendent traits and inspiring media exposure or inspiring media exposure and self-transcendent emotions. Second, the measure of inspirational media exposure is (necessarily) subjective and assessed people's perceptions rather than “actual” inspiring media exposure per se. However, previous content analytical research suggests that people's perceptions of inspiration from media are in line with content containing depictions of inspirational and transcendent themes (Dale et al., 2017a, Dale et al., 2017b). Thus, it can be argued that asking participants about one’s “most recent inspirational media encounter” indeed measured (at least to some degree) content that was transcendent in nature. Recalling previous media experiences is a common practice in entertainment research (see Oliver \& Raney, 2011). However, future research is encouraged to 
replicate these findings in an experimental setting with previously validated inspirational media content. Lastly, due to restrictions in survey length (primarily because of associated costs) only abbreviated personality scales, a limited number of character strengths, and a potentially nonexhaustive list of non-mediated inspiring activities could be used. Future research would benefit from using the full trait scales and a more comprehensive list of character strengths and inspiring activities for a more comprehensive assessment. Using full scales for the personality factors could potentially change the results since the current assessment fails to measure the full scales of the respective personality traits. However, the selected items were part of validated, full psychometric scales, thus measuring at least in part the construct in question. Consequently, we are confident our results have sufficient construct validity, but future research is needed to further verify our findings using full scale assessments.

Despite these limitations, the current study is important on a number of aspects. First, it provides compelling evidence that inspiring media is a common reception and socially shared phenomenon in the U.S. Second, it firmly establishes the significant role that transcendent character strengths play in the consumption of inspiring media. Third, it illuminates how inspiring media consumption contributes meaningfully to the day-to-day experience of selftranscendent emotions, over and beyond the influence of many variables, including nonmediated inspiring activities. Finally, it provides a solid basis for scholars to pursue the study of inspirational media in more detail. Better understanding how media content inspires and for whom it is inspiring is an important step in illuminating ways people can intentionally use media to better themselves, others, and humanity at large. 


\section{References}

Algoe, S. B., \& Haidt, J. (2009). Witnessing excellence in action: The “other-praising” emotions of elevation, gratitude, and admiration. The Journal of Positive Psychology, 4, 105-127. doi:10.1080/17439760802650519

Appel, M., Gnambs, T., \& Maio, G. (2012). A short measure of the need for affect. Journal of Personality Assessment, 94, 418-426. doi:10.1080/00223891.2012.666921

Bartlett, M.Y., \& DeSteno, D. (2006). Gratitude and prosocial behavior: Helping when it costs you. Psychological Science, 17, 319-325. doi:10.1111/j.1467-9280.2006.01705.x

Bartsch, A., Kalch, A., \& Oliver, M. B. (2014). Moved to think: The role of emotional media experiences in stimulating reflective thoughts. Journal of Media Psychology: Theories, Methods, and Applications, 26, 125-140. doi:10.1027/1864-1105/a000118

Bartsch, A. \& Viehoff, R. (2010). The use of media entertainment and emotional gratification. Procedia - Social and Behavioral Sciences, 5, 2247-2255. doi:10.1016/j.sbspro.2010.07.444

Berger, J., \& Milkman, K. L. (2012). What makes online content viral?. Journal of Marketing Research, 49, 192-205.

Bryant, J., \& Davies, J. (2006). Selective exposure processes. In J. Bryant \& P. Vorderer (Eds.), Psychology of entertainment (pp. 19-33). Mahwah, NJ: Lawrence Erlbaum Associates.

Clayton, R. B., Raney, A. A., Oliver, M. B., Neumann, D., Janicke-Bowles, S.H., Dale, K.R. (in press). Feeling transcendent?: Measuring psychophysiological responses to selftranscendent media content. Accepted for publication at Media Psychology.

Dale, K. R., Raney, A. A., Janicke, S. H., Baldwin, J., Rowlett, J., Wang, C., \& Zhao, D. (2017a, November). Narratives and self-transcendent emotions: A content analysis of 
inspirational movies and television shows. Paper presented at the annual meeting of the National Communication Association, Dallas, TX.

Dale, K. R., Raney, A. A., Janicke, S. H., Sanders, M., \& Oliver, M. B. (2017b). YouTube for good: A content analysis and examination of elicitors of self-transcendent media. Journal of Communication, 67, 897-919. doi:10.1111/jcom.12333

Diessner, R., Solom, R. C., Frost, N. K., Parsons, L., \& Davidson, J. (2008). Engagement with beauty: Appreciating natural, artistic, and moral beauty. Journal of Psychology, 142, 303329. doi:10.3200/jrlp.142.3.303-332

Elkins, D. N., Hedstrom, L. J., Hughes, L. L., Leaf, J. A., \& Saunders, C. (1988). Toward a humanistic-phenomenological spirituality: Definition, description, and measurement. Journal of Humanistic Psychology, 28, 5-18. doi:10.1177/0022167888284002

Emmons, R. A. (2006). Spirituality: Recent progress. In M. Csikszentmihalyi \& I. S. Csikszentmihalyi (Eds.), A life worth living: Contributions to positive psychology (pp. 62-84). New York, NY: Oxford University Press.

Emmons, R. A., \& McCullough, M. E. (2003). Counting blessings versus burdens: An experimental investigation of gratitude and subjective well-being in daily life. Journal of Personality and Social Psychology, 84, 377-389. doi:10.1037/0022-3514.84.2.377

Fredrickson, B. L. (2001). The role of positive emotions in positive psychology: The broadenand-build theory of positive emotions. American Psychologist, 56, 218-226. doi:10.4135/9781412956253.n75

Haidt, J. (2003). The moral emotions. In R. J. Davidson, K. R. Scherer, \& H. H. Goldsmith (Eds.), Handbook of affective sciences (pp. 852-870). Oxford, UK: Oxford University Press. 
Haidt, J., \& Morris, J. P. (2009). Finding the self in self-transcendent emotions. Proceedings of the National Academy of Sciences, 106, 7687-7688. doi:10.1073/pnas.0903076106

Haidt, J. \& Keltner, D. (2004). Appreciation of beauty and excellence. In C. Peterson \& M. E. P. Seligman (Eds.), Character strengths and virtues (pp. 537-551). Washington, DC: American Psychological Association Press.

Huffpost PR Team (2018, June, 27). HuffPost introduces The Good Kind: New interactive editorial initiative aimed at elevating stories about kindness. Huffington Post. Retrieved from https://www.huffingtonpost.com/entry/huffpost-introduces-the-goodkind_us_5b32b10ae4b0b745f1789e9a

Janicke, S. H., \& Oliver, M. B. (2017). The relationship between elevation, connectedness and compassionate love in meaningful films. Psychology of Popular Media Culture, 6, 274289. doi:10.1037/ppm0000105

Janicke, S. H., \& Raney, A. A. (2016). Media, spirituality, and well-being. In L. Reinecke, \& M. B. Oliver (Eds.), The Routledge handbook of media use and well-being (pp. 355-367). New York, NY: Routledge.

Ji, Q., Raney, A. A., Janicke-Bowles, S. H., Dale, K. R., Oliver, M. B., Reed, A., Seibert, J., \& Raney II, A. A. (2019). Spreading the good news: Analyzing socially shared inspirational news content. Journalism \& Mass Communication Quarterly, 96(3), 872-893. https://doi.org/10.1177/1077699018813096

Lyubomirsky, S., Dickerhoof, R., Boehm, J. K., \& Sheldon, K.M. (2011). Becoming happier takes both a will and a proper way: An experimental longitudinal intervention to boost well-being. Emotion, 11, 392-402. doi:10.1037/a0022575 
Ma, L. K., Tunney, R. J., \& Ferguson, E. (2017). Does gratitude enhance prosociality?: A metaanalytic review. Psychological Bulletin, 143, 601-635. doi:10.1037/bul0000103

McCullough, M. E., \& Tsang, J. (2004). Parent of the virtues? The prosocial contours of gratitude. In R. A. Emmons, \& M. E. McCullough (Eds.), The psychology of gratitude (pp. 123-141). New York, NY: Oxford University Press.

McCullough, M. E., Kilpatrick, S. D., Emmons, R. A., \& Larson, D. B. (2001). Is gratitude a moral affect? Psychological Bulletin, 127, 249-266. doi:10.1037/0033-2909.127.2.249

Oliver, M. B., Raney, A. A., Slater, M., Appel, M., Hartmann, T., Bartsch, A., Schneider, F., Janicke-Bowles, S. H., Krämer, N., Mares, M. L., Vorderer, P., Rieger, D., Dale, K. R., \& Das, H. H. J. (2018). Self-transcendent media experiences: Taking meaningful media to a higher level. Journal of Communication, 68, 380-389. doi:10.1093/joc/jqx020

Oliver, M. B., \& Raney, A. A. (2011). Entertainment as pleasurable and meaningful: Identifying hedonic and eudaimonic motivations for entertainment consumption. Journal of Communication, 61, 984-1004. doi:10.1111/j.1460-2466.2011.01585.X

Park, N., Peterson, C., \& Seligman, M. P. (2004). Strengths of character and well-being. Journal of Social and Clinical Psychology, 23, 603-619. doi:10.1521/jscp.23.5.603.50748

Peters, B. (2019, January 17). What 777,367,063 Facebook posts tell us about successful content in 2019 (New Research). Buffer.com. Retrieved from https://blog.bufferapp.com/facebook-marketing-2019

Peterson, C., \& Seligman, M. E. P. (2004). Character strengths and virtues: A handbook and classification. New York, NY: Oxford University Press. 
Piedmont, R. L. (1999). Does spirituality represent the sixth factor of personality? Spiritual transcendence and the five-factor model. Journal of Personality, 67, 985-1013. doi:10.1111/1467-6494.00080

Ramasubramanian, S. (2014). Media and spirituality. In M. B. Oliver, \& A. A. Raney (Eds.), Media and social life (pp. 46-63). New York, NY: Routledge.

Raney, A. A., Janicke, S. H., Oliver, M. B., Dale, K. R., Jones, R. P., \& Cox, D. (2018). Profiling the sources of and audiences for inspiring media content: A national survey. Mass Communication and Society, 21, 296-319. doi:10.1080/15205436.2017.1413195

Saroglou, V., Buxant, C., \& Tilquin, J. (2008). Positive emotions as leading to religion and spirituality. The Journal of Positive Psychology, 3, 165-173. doi:10.1080/17439760801998737

Schnall, S., Roper, J., \& Fessler, D. M. T. (2010). Elevation leads to altruistic behavior. Psychological Science, 21, 315-320. doi:10.1177/0956797609359882

Steger, M. F., Frazier, P., Oishi, S., \& Kaler, M. (2006). The meaning in life questionnaire: Assessing the presence of and search for meaning in life. Journal of Counseling Psychology, 53, 80-93. doi:10.1037/0022-0167.53.1.80

Stellar, J. E., Gordon, A. M., Piff, P. K., Cordaro, D., Anderson, C. L., Bai, Y., \& ... Keltner, D. (2017). Self-transcendent emotions and their social functions: Compassion, gratitude, and awe bind us to others through prosociality. Emotion Review, 9, 200-207. doi:10.1177/1754073916684557

Thrash, T. M., Elliot, A. J., Maruskin, L. A., \& Cassidy, S. E. (2010). Inspiration and the promotion of well-being: Tests of causality and mediation. Journal of Personality \& Social Psychology, 98, 488-506. doi:10.1037/a0017906 
Thrash, T. M., \& Elliot, A. J. (2003). Inspiration as a psychological construct. Journal of Personality and Social Psychology, 84, 871-889. doi:10.1037/0022-3514.84.4.871

USA Today Humankind (2016, January 7). Tell Humankind your story worth sharing! USA Today. Retrieved from https://www.usatoday.com/story/news/humankind/2015/07/29/humankind-your-storyworth-sharing/30829781/

Vago, D. R., \& Silbersweig, D. A. (2012). Self-awareness, self-regulation, and selftranscendence (S-ART): A framework for understanding the neurobiological mechanisms of mindfulness. Frontiers in Human Neuroscience, 6, 296. doi:10.3389/fnhum.2012.00296

Van Cappellen, P., Saroglou, V., Iweins, C., Piovesana, M., \& Fredrickson, B., L. (2013). Selftranscendent positive emotions increase spirituality through basic world assumptions. Cognition and Emotion, 27, 1378-1394. doi: 10.1080/02699931.2013.787395

Vorderer, P. (1992). Fernsehen als Handlung: Fernsehfilmrezeption aus motivationspsychologischer Perspektive. Berlin: Edition Sigma.

Wood, A. M., Froh, J. J., \& Geraghty, A. A. (2010). Gratitude and well-being: A review and theoretical integration. Clinical Psychology Review, 30, 890-905. doi:10.1016/j.cpr.2010.03.005

Yaden, D. B., Haidt, J., Hood, R. J., Vago, D. R., \& Newberg, A. B. (2017). The varieties of selftranscendent experience. Review of General Psychology, 21, 143-160. doi:10.1037/gpr0000102 
Table 1.

Recency of Having Felt Inspired by Different Media by Demographics

\begin{tabular}{|c|c|c|c|c|c|c|c|c|c|c|}
\hline & \multicolumn{2}{|c|}{ Gender } & \multicolumn{4}{|c|}{ Ethnicity/Race } & \multicolumn{4}{|c|}{ Education } \\
\hline & $\begin{array}{c}\text { Male } \\
(n=975)\end{array}$ & $\begin{array}{c}\text { Female } \\
(n=1041)\end{array}$ & $\begin{array}{c}\text { White } \\
(n=1306)\end{array}$ & $\begin{array}{c}\text { Black } \\
(n=236)\end{array}$ & $\begin{array}{c}\text { Hispanic } \\
(n=314)\end{array}$ & $\begin{array}{l}\text { Multi- } \\
\text { Racial } \\
(n=65)\end{array}$ & $\begin{array}{c}<\mathrm{HS} \\
(n=248)\end{array}$ & $\begin{array}{l}\text { HS/GED } \\
(n=596)\end{array}$ & $\begin{array}{c}\text { Some } \\
\text { college } \\
(n=519)\end{array}$ & $\begin{array}{c}\mathrm{BA}+ \\
(n=653)\end{array}$ \\
\hline \multirow[t]{2}{*}{ TV } & $3.76^{\mathrm{a}}$ & $4.06^{\mathrm{b}}$ & $3.87^{\mathrm{a}}$ & $4.01^{\mathrm{ab}}$ & $4.04^{b}$ & $3.98^{\mathrm{ab}}$ & $4.17^{a}$ & $4.00^{a}$ & $3.84^{b}$ & $3.79^{b}$ \\
\hline & (1.23) & (1.11) & (1.20) & (1.23) & (1.01) & (1.11) & (1.07) & (1.18) & (1.19) & (1.19) \\
\hline \multirow[t]{2}{*}{ Movie } & $3.55^{a}$ & $3.87^{b}$ & $3.68^{a}$ & $3.80^{a}$ & $3.73^{a}$ & $3.63^{\mathrm{a}}$ & $3.62^{\mathrm{a}}$ & $3.71^{\mathrm{a}}$ & $3.78^{\mathrm{a}}$ & $3.69^{\mathrm{a}}$ \\
\hline & (1.21) & (1.08) & (1.15) & (1.29) & (1.11) & $(1.22)$ & (1.31) & (1.18) & (1.13) & (1.09) \\
\hline \multirow[t]{2}{*}{ Radio/podcast } & $3.21^{\mathrm{a}}$ & $3.31^{a}$ & $3.15^{\mathrm{a}}$ & $3.54^{\mathrm{b}}$ & $3.53^{b}$ & $3.05^{\mathrm{a}}$ & $3.37^{a}$ & $3.15^{b}$ & $3.22^{\mathrm{ab}}$ & $3.35^{\mathrm{a}}$ \\
\hline & (1.3) & (1.38) & (1.39) & (1.42) & (1.25) & $(1.30)$ & (1.45) & (1.38) & (1.38) & (1.35) \\
\hline \multirow[t]{2}{*}{ Book } & $2.93^{\mathrm{a}}$ & $3.32^{b}$ & $3.17^{a}$ & $3.20^{\mathrm{ac}}$ & $2.94^{\mathrm{b}}$ & $2.82^{\mathrm{bc}}$ & $2.69^{a}$ & $2.98^{\mathrm{b}}$ & $3.06^{\mathrm{b}}$ & $3.46^{c}$ \\
\hline & (1.29) & (1.29) & (1.32) & (1.33) & (1.21) & (1.17) & (1.31) & $(1.32)$ & (1.25) & $(1.24)$ \\
\hline \multirow[t]{2}{*}{ Music } & $4.00^{a}$ & $4.37^{b}$ & $4.16^{\mathrm{ab}}$ & $4.25^{b}$ & $4.28^{\mathrm{b}}$ & $3.93^{\mathrm{ac}}$ & $4.13^{a}$ & $4.35^{a}$ & $4.18^{a}$ & $4.16^{\mathrm{a}}$ \\
\hline & $(1.20)$ & $(.96)$ & (1.12) & (1.19) & (.958) & (1.13) & (1.24) & (1.05) & (1.14) & (1.06) \\
\hline \multirow[t]{2}{*}{ News story } & $3.51^{a}$ & $3.72^{b}$ & $3.67^{a}$ & $3.73^{a}$ & $3.38^{\mathrm{b}}$ & $3.06^{\mathrm{b}}$ & $2.99^{a}$ & $3.60^{\mathrm{b}}$ & $3.58^{\mathrm{b}}$ & $3.88^{c}$ \\
\hline & (1.34) & (1.24) & (1.28) & $(1.40)$ & (1.25) & (1.33) & $(1.50$ & $(1.27)$ & (1.30) & (1.15) \\
\hline \multirow[t]{2}{*}{ Online video } & $3.21^{\mathrm{a}}$ & $3.68^{\mathrm{b}}$ & $3.35^{\mathrm{a}}$ & $3.40^{\mathrm{a}}$ & $3.84^{\mathrm{b}}$ & $3.51^{a b}$ & $3.16^{\mathrm{a}}$ & $3.36^{a b}$ & $3.58^{\mathrm{c}}$ & $3.51^{\mathrm{c}}$ \\
\hline & $(1.44)$ & (1.31) & $(1.40)$ & (1.52) & (1.24) & $(1.27)$ & (1.63) & (1.38) & (1.34) & (1.33) \\
\hline \multirow[t]{2}{*}{ Social Media } & $2.83^{a}$ & $3.79^{b}$ & $3.22^{a}$ & $3.35^{a}$ & $3.72^{\mathrm{b}}$ & $3.12^{\mathrm{a}}$ & $2.92^{a}$ & $3.43^{b}$ & $3.40^{\mathrm{b}}$ & $3.29^{b}$ \\
\hline & (1.59) & $(1.44)$ & (1.61) & (1.66) & (1.38) & $(1.45)$ & (1.81) & (1.48) & (1.54) & $(1.53)$ \\
\hline \multirow[t]{2}{*}{ Total } & $3.37^{\mathrm{a}}$ & $3.76^{b}$ & $3.53^{\mathrm{a}}$ & $3.66^{b}$ & $3.68^{b}$ & $3.42^{\mathrm{a}}$ & $3.38^{\mathrm{a}}$ & $3.55^{b}$ & $3.58^{\mathrm{b}}$ & $3.64^{\mathrm{b}}$ \\
\hline & $(.889)$ & $(.762)$ & $(.844)$ & $(1.02)$ & $(.708)$ & $(.808)$ & $(.898)$ & $(.834)$ & $(.845)$ & $(.840)$ \\
\hline
\end{tabular}

Note: Cells include means and standard deviations (in parentheses). Different superscripts $\left({ }^{\mathrm{a}}{ }^{\mathrm{b}}\right.$ ) within rows indicate significance between groups at $p<.05$ for each category (i.e., gender, ethnicity, education).

Significant results for Gender were obtained for ( $F(1,1979))$ : TV: 31.61, $p<.001$; Movie: 38.25, $p<.001$; Books:43,97, $p<.001$; Music: 56.97, $p<.001$, News: 13.95, $p<.001$; Online video: 59.65, $p<.001$; Social Media: 196.87, $p<.001$. Across all inspiring media multivariate test: $F(8,1972)=31.72, p<.001$, partial $\eta^{2}=.114$

Significant results for Race were obtained for ( $F(3,1877)$ ): Radio: $9.93 p<.001$; Books: 3.92, $p=.008$; News: 8.24, $p<.001$; Online video: 10.17, $p<.001$; Social Media: 8.51, $p<.001$. Across all inspiring media multivariate test: $F(24,5616)=6.48, p=.005$, partial $\eta^{2}=.027$; Data from Other race category $(n=95)$ are not reported.

Significant results for Education were obtained for ( $F$ (3,1977)): TV: 7.98, $p<.001$; Radio: $2.74 p=.042$; Books: 27.26, $p<.001$; News: 29.13, $p<.001$; Online video: 6.09, $p<.001$; Social Media: 6.50, $p<.001$; Across all inspiring media multivariate test: $F(24,5916)=12.67, p<.001$, partial $\eta^{2}=.049$ 
Table 2.

Recency of Having Felt Inspired by Different Media by Demographics Continued

\begin{tabular}{|c|c|c|c|c|c|c|c|c|c|}
\hline & \multicolumn{4}{|c|}{ Age } & \multicolumn{2}{|c|}{ Relationship status } & \multicolumn{3}{|c|}{ Party Affiliation } \\
\hline & $\begin{array}{c}18-29 \\
(n=407)\end{array}$ & $\begin{array}{c}30-44 \\
(n=504)\end{array}$ & $\begin{array}{c}45-59 \\
(n=536)\end{array}$ & $\begin{array}{c}60+ \\
(n=570)\end{array}$ & $\begin{array}{c}\text { Married } \\
\text { or living } \\
\text { with a } \\
\text { partner } \\
(n=1118)\end{array}$ & $\begin{array}{c}\text { Single, } \\
\text { widowed, } \\
\text { divorced, } \\
\text { separated } \\
(n=898)\end{array}$ & $\begin{array}{c}\text { Republican } \\
(n=510)\end{array}$ & $\begin{array}{l}\text { Independent } \\
\quad(n=659)\end{array}$ & $\begin{array}{c}\text { Democrat } \\
(n=697)\end{array}$ \\
\hline \multirow[t]{2}{*}{ TV } & $3.69^{\mathrm{a}}$ & $3.78^{\mathrm{a}}$ & $4.02^{\mathrm{b}}$ & $4.07^{\mathrm{b}}$ & $3.91^{\mathrm{a}}$ & $3.92^{\mathrm{a}}$ & $3.90^{\mathrm{a}}$ & $3.78^{\mathrm{a}}$ & $4.07^{b}$ \\
\hline & (1.11) & $(1.22)$ & (1.14) & (1.19) & (1.19) & (1.17) & (1.14) & $(1.20)$ & (1.10) \\
\hline \multirow[t]{2}{*}{ Movie } & $3.54^{a}$ & $3.78^{b}$ & $3.91^{b}$ & $3.57^{a}$ & $3.71^{\mathrm{a}}$ & $3.72^{a}$ & $3.64^{a}$ & $3.65^{a}$ & $3.84^{\mathrm{b}}$ \\
\hline & $(1.02)$ & (1.13) & $(1.10)$ & $(1.30)$ & (1.18) & (1.15) & (1.17) & $(1.18)$ & $(1.08)$ \\
\hline \multirow[t]{2}{*}{ Radio/podcast } & $3.33^{a}$ & $3.36^{a}$ & $3.31^{a}$ & $3.07^{a}$ & $3.24^{a}$ & $3.29^{a}$ & $3.25^{a}$ & $3.29^{a}$ & $3.31^{\mathrm{a}}$ \\
\hline & (1.31) & (1.31) & $(1.42)$ & $(1.46)$ & (1.38) & (1.38) & (1.37) & $(1.40)$ & $(1.32)$ \\
\hline \multirow[t]{2}{*}{ Book } & $2.96^{\mathrm{a}}$ & $3.21^{\mathrm{b}}$ & $2.98^{a}$ & $3.30^{\mathrm{b}}$ & $3.17^{a}$ & $3.07^{a}$ & $3.15^{a}$ & $3.11^{a}$ & $3.10^{a}$ \\
\hline & (1.11) & $(1.30)$ & $(1.31)$ & (1.39) & (1.34) & $(1.24)$ & (1.37) & $(1.26)$ & $(1.25)$ \\
\hline \multirow[t]{2}{*}{ Music } & $4.26^{a}$ & $4.15^{a}$ & $4.23^{a}$ & $4.14^{\mathrm{a}}$ & $4.13^{a}$ & $4.26^{\mathrm{b}}$ & $4.17^{a}$ & $4.15^{a}$ & $4.23^{a}$ \\
\hline & $(.991)$ & (1.11) & (1.09) & (1.18) & (1.13) & (1.06) & (1.14) & $(1.12)$ & $(1.05)$ \\
\hline \multirow[t]{2}{*}{ News story } & $3.39^{a}$ & $3.71^{b}$ & $3.57^{b}$ & $3.72^{b}$ & $3.61^{a}$ & $3.63^{a}$ & $3.54^{a}$ & $3.59^{a}$ & $3.67^{a}$ \\
\hline & (1.19) & (1.24) & (1.30) & $(1.40)$ & (1.29) & (1.30) & (1.31) & (1.29) & (1.29) \\
\hline \multirow[t]{2}{*}{ Online video } & $3.84^{a}$ & $3.73^{a}$ & $3.49^{b}$ & $2.83^{c}$ & $3.35^{\mathrm{a}}$ & $3.56^{b}$ & $3.29^{a}$ & $3.51^{b}$ & $3.53^{\mathrm{cb}}$ \\
\hline & (1.08) & $(1.26)$ & (1.38) & (1.53) & $(1.40)$ & (1.37) & (1.44) & (1.37) & (1.35) \\
\hline \multirow[t]{2}{*}{ Social Media } & $3.71^{\mathrm{a}}$ & $3.51^{\mathrm{ab}}$ & $3.41^{\mathrm{b}}$ & $2.74^{\mathrm{C}}$ & $3.26^{\mathrm{a}}$ & $3.38^{a}$ & $3.28^{\mathrm{a}}$ & $3.19^{a}$ & $3.46^{\mathrm{b}}$ \\
\hline & $(1.29)$ & $(1.53)$ & $(1.57)$ & $(1.71)$ & $(1.59)$ & $(1.59)$ & $(1.58)$ & (1.61) & $(1.55)$ \\
\hline \multirow[t]{2}{*}{ Total } & $3.58^{\mathrm{a}}$ & $3.65^{a}$ & $3.62^{a}$ & $3.42^{b}$ & $3.54^{\mathrm{a}}$ & $3.60^{\mathrm{a}}$ & $3.53^{\mathrm{a}}$ & $3.54^{\mathrm{a}}$ & $3.64^{b}$ \\
\hline & $(.747)$ & $(.902)$ & $(.824)$ & $(.878)$ & $(.853)$ & $(.845)$ & $(.841)$ & $(.869)$ & $(.803)$ \\
\hline
\end{tabular}

Note. Cells include means and standard deviations (in parentheses). Different superscripts $\left({ }^{\mathrm{a} b}\right)$ within rows indicate significance between groups at $p<.05$ for each category (i.e., gender, ethnicity, education).

Significant results for Age were obtained for (F (3,1977)): TV: 11.4, $p<.001$; Movie: 10.89, $p<.001$; Radio: $4.68 p=.003$; Books: 8.12, $p<.001$; News: 6.08, $p<.001$; Online video: 56.95, $p<.001$; Social Media: 36.03, $p<.001$; Across all inspiring media multivariate test: $F(24,5916)=19.39, p<.001$, partial $\eta^{2}=.073$.

Significant results for Relationship Status were obtained for $(F(1,1979))$ : Music: 6.59, $p=.010$; Online video: 11.00, $p=.001$; Across all inspiring media multivariate test: $F(8,1972)=2.76, p=.005$, partial $\eta^{2}=.011$

Significant results for Political Party Affiliation were obtained for ( $F(2,1836)$ ): TV: 10.73, $p<.001$; Movie: 6.05, $p=.002$; Online video: 4.93, $p=.007$; Social Media: 4.99, $p=.007$; Across all inspiring media multivariate test: $F(16,3660)=3.24, p<.001$, partial $\eta^{2}=.014$

Party affiliation was assessed with the question: "In politics today, do you consider yourself a Republican, Democrat, or independent”? Data from Other/Refused category ( $n=150)$ are not reported. 
Table 3.

Predictors of Inspiring Media Experiences

\begin{tabular}{|c|c|c|c|c|}
\hline & & $\beta$ & $R^{2} / R^{2}$ Change & F/F Change \\
\hline \multirow[t]{3}{*}{ Step $1^{\mathrm{a}}$} & Gender & $.219^{* * *}$ & .053 & $36.533,1968^{* * *}$ \\
\hline & Age & -.040 & & \\
\hline & Marital Status & .014 & & \\
\hline \multirow[t]{4}{*}{ Step $2^{b}$} & Education & & .005 & $3.81_{3,1965}{ }^{*}$ \\
\hline & HS/GRE & .023 & & \\
\hline & Some College & .050 & & \\
\hline & $\mathrm{BA}+$ & $.097^{* *}$ & & \\
\hline \multirow[t]{5}{*}{ Step $3^{c}$} & Ethnicity & & .004 & $1.974,1961$ \\
\hline & White & .004 & & \\
\hline & Black & .043 & & \\
\hline & Hispanic & .042 & & \\
\hline & Multi-Racial & -.030 & & \\
\hline \multirow[t]{3}{*}{ Step $4^{\mathrm{d}}$} & Attendance & & .007 & $7.07_{2,1959^{* * *}}$ \\
\hline & Religious & .055 & & \\
\hline & Spiritual & .038 & & \\
\hline \multirow[t]{4}{*}{ Step 5} & Eudaimonic Traits & & .031 & $22.363,1956^{* * *}$ \\
\hline & Need for Affect & $.142^{* * *}$ & & \\
\hline & Perspective Taking & .019 & & \\
\hline & Empathic Concern & $.069^{* *}$ & & \\
\hline \multirow[t]{4}{*}{ Step 6} & Transcendent Traits & & .071 & $56.09_{3,1953^{* * *}}$ \\
\hline & Universality & $.126^{* * *}$ & & \\
\hline & Gratitude & $.206^{* * *}$ & & \\
\hline & Search for Meaning & $.102^{* * *}$ & & \\
\hline
\end{tabular}

Note. ${ }^{*} p<.05 .{ }^{* *} p<.01 .{ }^{* * *} p<.001$. Model $F(18,1954)=22.38$, adj. $R^{2}=.163, p<.001$

${ }^{\mathrm{a}}$ Gender was coded as males $=1$, females $=2$. Marital status was coded as $1=$ not married, $2=$ married.

bThe omitted reference category for education was less than a high school diploma.

"The omitted reference category for ethnicity was "other" ethnicity

${ }^{\mathrm{d}}$ Religious and spiritual attendance was used as continuous variable

No multicollinearity issues were observed in the model. The tolerance for each variable was $>.6$ and the VIF $<2.0$.

The same results ensued when using the frequency of inspiring media experience measure as outcome variable. The explained variance for eudaimonic traits was $5 \%$, and for the transcendent traits was $8.6 \%$. Thus, the current measure results in a more conservative estimation. 
Table 4.

Predictors of Self-Transcendent Emotional Experiences

\begin{tabular}{|c|c|c|c|c|}
\hline & & $\beta$ & $R^{2} / R^{2}$ Change & F/F Change \\
\hline \multirow[t]{3}{*}{ Step 1} & Gender & $.156^{* * *}$ & .030 & $19.29_{3,1891}{ }^{* * *}$ \\
\hline & Age & $.093^{* * *}$ & & \\
\hline & Marital Status & -.025 & & \\
\hline \multirow[t]{4}{*}{ Step 2} & Education & & .024 & $16.08_{3,1888^{* * *}}$ \\
\hline & HS/GRE & $-.160^{* * *}$ & & \\
\hline & Some College & $-.072^{*}$ & & \\
\hline & $\mathrm{BA}+$ & .013 & & \\
\hline \multirow[t]{5}{*}{ Step 3} & Ethnicity & & .003 & $1.70_{4,1884}$ \\
\hline & White & -.072 & & \\
\hline & Black & -.045 & & \\
\hline & Hispanic & -.010 & & \\
\hline & Multi-Racial & .010 & & \\
\hline \multirow[t]{3}{*}{ Step 4} & Attendance & & .050 & $53.01_{2,1882^{* * *}}$ \\
\hline & Religious & .040 & & \\
\hline & Spiritual & $.203^{* * *}$ & & \\
\hline \multirow[t]{6}{*}{ Step 5} & Non-Media Inspiring Activities & & .102 & $48.45_{5,1877^{* * *}}$ \\
\hline & Being with friends & $.119^{* * *}$ & & \\
\hline & Meditate & $.142^{* * *}$ & & \\
\hline & Gardening, being outside & $.099^{* * *}$ & & \\
\hline & Yoga & $.052^{*}$ & & \\
\hline & $\begin{array}{l}\text { Praying (outside of religious } \\
\text { context) }\end{array}$ & $.241^{* * *}$ & & \\
\hline \multirow[t]{9}{*}{ Step 6} & Overall Media Exposure & & .009 & $2.79_{8,1869^{* *}}$ \\
\hline & Radio & -.015 & & \\
\hline & TV & .012 & & \\
\hline & Film & $-.056^{*}$ & & \\
\hline & Social Media & $.057^{*}$ & & \\
\hline & Books & .022 & & \\
\hline & Music & .036 & & \\
\hline & Online Video & $.055^{*}$ & & \\
\hline & News & -.011 & & \\
\hline \multirow[t]{2}{*}{ Step 7} & Transcendent Emotions & & .187 & $589.83_{1,1868}^{* * *}$ \\
\hline & $\begin{array}{l}\text { Self-transcendent Emotions } \\
\text { (Wave 1) }\end{array}$ & $.528^{* * *}$ & & \\
\hline \multirow[t]{2}{*}{ Step 8} & Inspiring Media & & .100 & $377.61_{1,1867}^{* * *}$ \\
\hline & $\begin{array}{l}\text { Recent Inspiring Media Experiences } \\
\text { (Wave 2) }\end{array}$ & $.365^{* * *}$ & & \\
\hline
\end{tabular}


All variables were measured on a continuous scale

Media experiences were measured with the combines score of the recency with which participants felt touched moved or inspired across eight different types of media.

The same results were obtained when using the overall frequency of inspiring media experience measure, which explained slightly more variance (13.9\%) of self-transcendent emotions, indicating that the used measure of recent inspiring media experiences is a more conservative measure. 